\title{
Survey of Drug Information Database Preferences among Staff from Selected British Columbia Health Authorities
}

\author{
Yiu-Ching Jennifer Wong, Candy Lee, and Adil Virani
}

Can J Hosp Pharm. 2020;73(4):257-65

\begin{abstract}
Background: With the increasing use of electronic point-of-care resources, it is imperative to clearly understand what health professionals consider valuable when selecting a drug information database. A current analysis of the preferences of staff in selected British Columbia health authorities was deemed helpful for determining which electronic drug information database should be purchased.
\end{abstract}

Objectives: To determine the factors that BC hospital pharmacists, nurses, and other health professionals value in an electronic drug information database and to better understand the general preferences of staff in choosing between the Lexicomp and Micromedex databases.

Methods: An electronic survey was created for data collection. The survey was open from August 10 to September 15, 2018, and again from November 11 to December 7, 2018. The survey link was sent by e-mail to staff in the following health authorities: Fraser Health, Providence Health Care, Provincial Health Services Authority, and Vancouver Coastal Health. Qualitative and quantitative methods were used to analyze the survey data.

Results: A total of 247 responses were received, of which 145 (58.7\%) were complete. Completed surveys were received from 77 pharmacists, 52 nurses, and 16 other health professionals. Participants ranked dosing information and ease of use as the most important factors that they considered when choosing a drug information database. There were no significant differences between the Lexicomp and Micromedex resources in terms of usability, quality, and preference.

Conclusions: This survey provided insights into what $B C$ health authority staff perceive as important when utilizing a drug information database. Those considering either renewing or initiating a subscription to an online drug information database can use these results to better understand the preferences of health care professionals. Survey respondents ranked dosing information and ease of use as the 2 most important factors in selecting a drug information database. Pharmacists were more particular about using their preferred database than were other health professionals.

Keywords: drug information databases, pharmacists, nurses, health authority staff, preferences

\section{RÉSUMÉ}

Contexte : Avec I'utilisation croissante de ressources électroniques aux points de services, il est impératif de bien comprendre ce que les professionnels de la santé estiment important lorsqu'ils choisissent une base de données sur les médicaments. Une analyse actuelle des préférences des membres du personnel des autorités sanitaires sélectionnées de la Colombie-Britannique a été jugée utile pour déterminer le type de base de données sur les médicaments à acheter.

Objectifs : Déterminer quels facteurs sont importants pour les pharmaciens d'hôpitaux, les infirmiers et les autres professionnels de la santé de la C.-B. lors du choix d'une base de données électronique sur les médicaments et mieux cerner les préférences générales des membres du personnel lorsqu'ils choisissent entre les bases de données Lexicomp et Micromedex.

Méthodes : Un sondage électronique a servi à la collecte des données. II s'est déroulé du 10 août au 15 septembre 2018, et à nouveau du 11 novembre au 7 décembre 2018. Les membres du personnel des autorités sanitaires suivantes ont reçu le lien menant au sondage : Fraser Health, Providence Health Care, Provincial Health Services Authority et Vancouver Coastal Health. L'analyse des données a été effectuée à l'aide de méthodes qualitatives et quantitatives.

Résultats : Les investigateurs ont reçu 247 réponses, dont 145 étaient complètes (58,7\%). Soixante-dix-sept (77) pharmaciens, 52 infirmiers et 16 autres professionnels de la santé ont dument rempli le sondage. Les participants ont indiqué que les renseignements sur le dosage et la facilité d'utilisation étaient les deux facteurs les plus importants à prendre en compte lors du choix d'une base de données sur les médicaments. Aucune différence significative n'est ressortie entre les bases de données Lexicomp et Micromedex quant à l'opérabilité, la qualité et la préférence.

Conclusions : Ce sondage a permis de fournir un aperçu sur ce que les membres du personnel des autorités sanitaires de la C.-B. percevaient comme important pour l'utilisation d'une base de données sur les médicaments. Les personnes qui ont l'intention de renouveler ou de souscrire un abonnement à une base de données sur les médicaments en ligne peuvent utiliser ces résultats pour mieux cerner les préférences des professionnels de la santé. Les répondants ont indiqué que les renseignements sur le dosage et la facilité d'utilisation étaient les deux facteurs les plus importants à prendre en compte lors du choix d'une base de données sur les médicaments. Les pharmaciens étaient moins disposés que les autres professionnels de la santé à changer leur base de données préférée pour une autre.

Mots-clés : base de données sur les médicaments, pharmaciens, infirmiers, membres du personnel des autorités sanitaires, préférences 


\section{INTRODUCTION}

As the volume of drug information expands, it becomes essential for health professionals to have a comprehensive, accurate, and efficient drug information resource readily available. The rapid advancement of technology enables health professionals to shift from physical reference books to electronic drug information databases, either in web-based or app-based format. Online drug information databases are accessible for free or through subscriptions. Despite the numerous databases available, most health authorities in British Columbia have limited resources and purchase a single electronic drug information database subscription at a time. Therefore, it is in the health authorities' interest to subscribe to the most well-rounded and cost-effective online database.

Subscription decisions should be based on the perceptions and preferences of health professionals (i.e., the users) regarding the quality, performance, usability, and value of the drug information databases that are available. A study conducted in 2010 compared BC hospital pharmacists' preferences concerning several drug information databases according to their usability and quality. ${ }^{1}$ To the best of our knowledge, there have been no studies investigating other Canadian health professionals' opinions. Given that online resources develop rapidly, a more up-to-date analysis is needed to understand what BC health authorities' staff members consider most important when choosing an online drug information database.

Lexicomp (Wolters Kluwer) and Micromedex (IBM Corporation) are the 2 electronic drug information databases to which BC health authorities currently subscribe most often. Since 2012, the Fraser Health Authority, Providence Health Care, the Provincial Health Services Authority, and Vancouver Coastal Health in the Lower Mainland have subscribed to both the web-based and the app-based versions of Lexicomp, with the web-based version being available on desktop computers through each health authority's intranet. Hospital staff can also download the app-based version to their personal or work cellphones. Of these 4 health authorities, only the Provincial Health Services Authority has active subscriptions to both Lexicomp and Micromedex (web-based version for both). The proportion of staff members in this health authority using Lexicomp or Micromedex as their main online drug resource varies by site. Notably, the Micromedex app is not part of the Provincial Health Services Authority's subscription. In fact, this app was free to the public during our study period. The web-based Micromedex database was recently revamped to incorporate features such as "ask Watson" and Canadianspecific drug information. To test the revised version, the publisher of Micromedex offered all of the health authorities in the Lower Mainland temporary access to the webbased database from August 2 to December 7, 2018. With the database subscriptions of several health authorities up for renewal, the availability of trial access to the web-based version of Micromedex, concurrent with ongoing access to Lexicomp, presented a good opportunity to conduct a program evaluation study and to investigate staff preferences between the 2 online drug resources.

For this quantitative and qualitative program evaluation analysis, we created a survey to investigate the main factors that staff members of Fraser Health, Providence Health Care, the Provincial Health Services Authority, and Vancouver Coastal Health take into consideration when choosing a web-based drug information database. In addition, we investigated staff members' general preference between Lexicomp and Micromedex (web-based versions) as their primary drug information database.

\section{METHODS}

A prospective, cross-sectional survey was created online via Qualtrics software (see Appendix 1, available at https://www. cjhp-online.ca/index.php/cjhp/issue/view/199/showToc). The online survey was initially available to potential participants between August 10 and September 15, 2018. This period yielded a low number of completed responses, so the survey was reopened from November 11 to December 7, 2018. The survey was exempted from Fraser Health ethics review because it was considered a program evaluation study.

A convenience sampling method was used. Information about this program evaluation and a link to the anonymous survey were distributed by e-mail to the 480 pharmacists employed at the time by Lower Mainland Pharmacy Services, with weekly reminder e-mails. Survey information and the link were also sent by e-mail to directors and managers of other health professionals within the 4 health authorities for further distribution to physicians and nurses, with weekly reminder e-mails. Only individuals who completed the survey were included in the analysis. All participants were asked to sign a consent form on page 1 of the electronic questionnaire. A link to the revised web-based version of Micromedex was embedded in the survey for participants who were new to the database, to allow experimentation before completing the survey.

The survey consisted of 14 questions (see Appendix 1). Partial responses were saved for up to $24 \mathrm{~h}$, allowing participants to return to where they left off. Participants had to complete each question before proceeding to the next one.

\section{Content of Survey}

Collection of demographic information: Participants were asked about their profession, number of years practising in a hospital setting, primary role in practice, prior experience with the Lexicomp and Micromedex databases, and frequency and purpose of using the drug information databases. 
Evaluation of factors deemed important to participants: Participants were asked to choose the top 3 factors influencing their choice of a preferred drug information database. A list of factors based on a previous publication ${ }^{2}$ was presented to participants. Distribution of the favoured factors was stratified by profession.

Evaluation of database usability: Participants were asked to complete a usability questionnaire for the Lexicomp and/ or Micromedex database. The usability questionnaire was adapted from previous publications. ${ }^{3,4}$ For each of 7 usability domains for each database (database layout, navigation, speed, accuracy of content, amount of information, capability to solve drug-related questions, and user satisfaction), the answer options were presented as a 5-point Likert scale, ranging from "strongly disagree" to "strongly agree". A mean score was calculated for each domain within each database.

Evaluation of overall quality and preference: Participants' thoughts about the overall quality of the 2 databases were determined by asking participants to choose either Lexicomp or Micromedex as the drug information database they considered as having better quality. Participants were similarly asked about their overall preference between the 2 drug information databases. The distribution of preference was stratified by profession.

Evaluation of willingness to switch from a preferred database: Participants' willingness to switch from a preferred database was assessed by cost. More specifically, participants were asked to choose the relative price reduction (as a percentage $[10 \%, 30 \%, 50 \%, 70 \%]$ or no preference) that would justify the cost-effectiveness of switching to a less preferred database. ${ }^{5}$

\section{Statistical Analysis}

Data regarding differences in usability score between the Lexicomp and Micromedex databases were analyzed quantitatively with descriptive (mean scores with 95\% confidence intervals) and inferential (unpaired 2-sample $t$ tests) statistics. The statistical analyses were performed with Excel software (Microsoft Corporation). Values of $p$ below 0.05 were considered statistically significant.

\section{Qualitative Analysis}

Bar graphs were used to illustrate the distribution of participants' overall database preferences, the databases' overall quality, and participants' willingness to switch from their preferred database.

\section{RESULTS}

Of the 247 responses received, 145 (58.7\%) were complete. Most of the participants were pharmacists (77 [53.1\%]) and nurses (52 [35.9\%]). The other health professionals included nurse practitioners and physicians, among others (16 [11.0\%]) (Figure 1).
Instead of sending the survey information and link through the survey software (Qualtrics), we relied on pharmacy leaders to distribute the survey invitation to all relevant health professionals. Therefore, the total number of health professionals (other than pharmacists) who received the e-mail with the survey link was unknown. We were also unable to determine the number of e-mail messages that were received, opened, or read. As a result, the response rate in relation to the number of health professionals in the 4 health authorities could not be accurately calculated. The 77 pharmacists who completed the survey represented $16.0 \%$ of the 480 hospital pharmacists to whom the survey link was sent, assuming that all e-mail addresses in the Lower Mainland distribution list for pharmacists were active. Nonetheless, when we examined the demographic data in Table 1, particularly years of practice and primary roles in practice, we found that participants in this survey accurately represented health professionals in British Columbia. ${ }^{6}$

\section{Characteristics of Participants}

Most participants (92 [63.4\%]) had been practising for more than 10 years, and most (102 [70.3\%]) worked in a direct patient care setting (Table 1). Most of the pharmacists reported using a drug information database a few times a day to search for drug dosages, drug interactions, and adverse drug reactions (Table 2). The other health professionals mostly reported using a drug information database weekly for similar reasons (Table 2).

\section{Factors Deemed Important to Participants}

When deciding on a drug information database, factors such as dosing information, ease of use, and drug interaction information had the strongest influence on pharmacists' decisions. Nurses considered factors such as dosing information, ease of use, and IV compatibilities as being most important. In addition to dosing information and ease of use, the other health professionals thought that information about approved indications was a crucial element (Table 3).

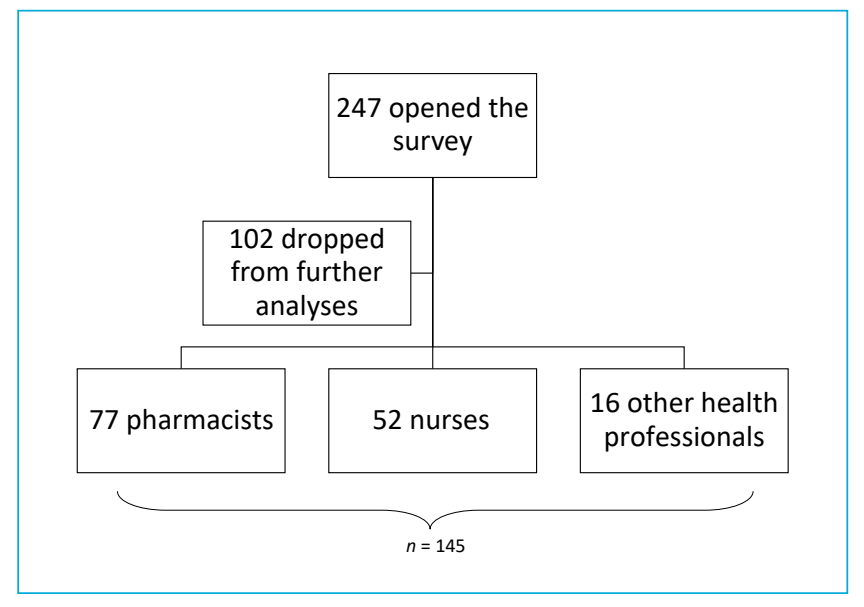

FIGURE 1. Flow chart for responses to the survey. 


\section{TABLE 1. Characteristics of Participants}

Health Profession; No. (\%) of Respondents*

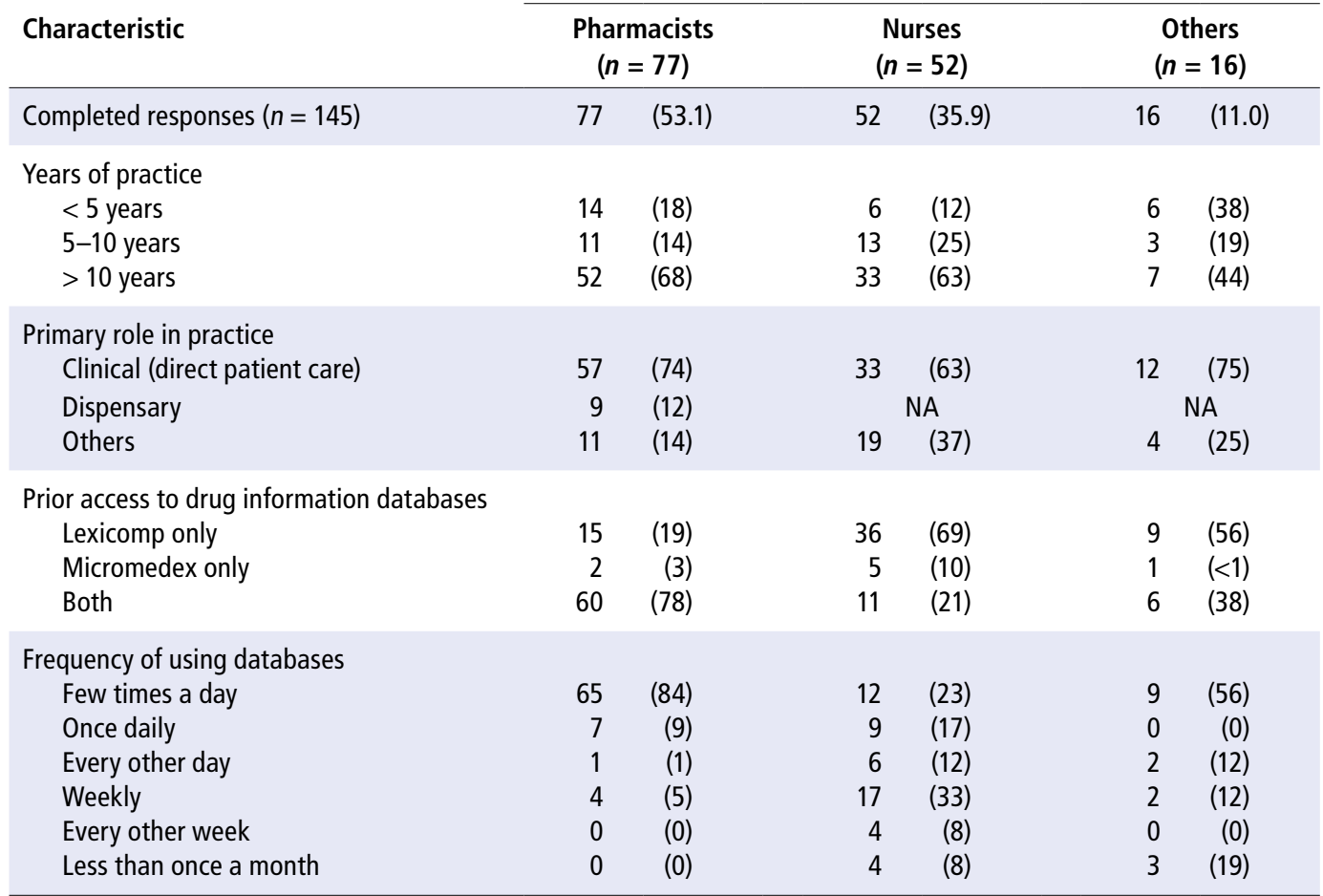

NA = not applicable.

*For the first row, the denominator for calculating percentages was 145 (the number of complete survey responses). For all subsequent rows, the denominators were the $n$ values at the top of each column (the number of complete survey responses in each category of health professionals).

\section{TABLE 2. Purposes for Use of Drug Information Databases}

\begin{tabular}{|c|c|c|c|c|c|c|}
\hline \multirow{3}{*}{$\begin{array}{l}\text { Purpose }^{\dagger} \\
\text { Adverse drug reactions }\end{array}$} & \multicolumn{6}{|c|}{ Health Profession; No. (\%) of Respondents* } \\
\hline & \multicolumn{2}{|c|}{$\begin{array}{c}\text { Pharmacists } \\
(n=77)\end{array}$} & \multicolumn{2}{|c|}{$\begin{array}{l}\text { Nurses } \\
(n=52)\end{array}$} & \multicolumn{2}{|c|}{$\begin{array}{c}\text { Others } \\
(n=16)\end{array}$} \\
\hline & 71 & $(92)$ & 35 & (67) & 13 & $(81)$ \\
\hline Approved indications & 40 & $(52)$ & 22 & (42) & 9 & (56) \\
\hline Contraindications & 41 & $(53)$ & 32 & $(62)$ & 13 & $(81)$ \\
\hline Drug dosages & 70 & $(91)$ & 35 & $(67)$ & 15 & (94) \\
\hline Drug identification & 12 & $(16)$ & 18 & (35) & 2 & $(12)$ \\
\hline Drug interactions & 71 & (92) & 30 & $(58)$ & 14 & (88) \\
\hline IV compatibilities & 32 & $(42)$ & 41 & $(79)$ & 2 & $(12)$ \\
\hline Patient counselling information & 29 & $(38)$ & 18 & $(35)$ & 8 & $(50)$ \\
\hline Pharmacokinetic parameters & 58 & $(75)$ & 6 & $(12)$ & 5 & (31) \\
\hline Pregnancy and lactation & 29 & (38) & 7 & $(13)$ & 4 & (25) \\
\hline Toxicology & 17 & $(22)$ & 8 & $(15)$ & 0 & $(0)$ \\
\hline Others & 5 & (6) & 3 & (6) & 2 & $(12)$ \\
\hline
\end{tabular}

*For all rows, the denominators were the $n$ values at the top of each column (the number of complete survey responses in each category of health professionals).

${ }^{\dagger}$ Respondents could select as many responses as were appropriate to their practice. 
TABLE 3. Factors Deemed Important by Health Professionals

\begin{tabular}{|c|c|c|c|c|c|c|c|c|}
\hline \multirow{3}{*}{$\begin{array}{l}\text { Factor* } \\
\text { Dosing information }\end{array}$} & \multicolumn{8}{|c|}{ Health Profession; No. (\%) of Respondents ${ }^{\dagger}$} \\
\hline & \multicolumn{2}{|c|}{$\begin{array}{c}\text { Pharmacists } \\
(n=77)\end{array}$} & \multicolumn{2}{|c|}{$\begin{array}{l}\text { Nurses } \\
(n=52)\end{array}$} & \multicolumn{2}{|c|}{$\begin{array}{l}\text { Others } \\
(n=16)\end{array}$} & \multicolumn{2}{|c|}{$\begin{array}{c}\text { All } \\
(n=145)\end{array}$} \\
\hline & 41 & (53) & 17 & (33) & 8 & $(50)$ & 66 & (46) \\
\hline Ease of use & 32 & $(42)$ & 26 & $(50)$ & 10 & $(62)$ & 68 & (47) \\
\hline Drug interaction information & 30 & (39) & 8 & $(15)$ & 3 & $(19)$ & 41 & (28) \\
\hline Canadian-specific drug information & 20 & $(26)$ & 13 & $(25)$ & 2 & $(12)$ & 35 & (24) \\
\hline Pharmacokinetic information & 19 & $(25)$ & 2 & (4) & 0 & (0) & 21 & (14) \\
\hline Adverse drug events & 19 & $(25)$ & 8 & $(15)$ & 3 & $(19)$ & 30 & $(21)$ \\
\hline Availability of app version & 14 & $(18)$ & 6 & $(12)$ & 2 & $(12)$ & 22 & $(15)$ \\
\hline Comparative efficacy of drugs & 10 & $(13)$ & 1 & (2) & 0 & (0) & 11 & (8) \\
\hline Patient management/monitoring parameters & 8 & $(10)$ & 10 & (19) & 3 & $(19)$ & 21 & (14) \\
\hline Screen layout & 6 & (8) & 5 & $(10)$ & 2 & $(12)$ & 13 & (9) \\
\hline Side effects & 6 & (8) & 10 & (19) & 2 & $(12)$ & 18 & $(12)$ \\
\hline IV compatibilities & 6 & (8) & 19 & $(37)$ & 0 & (0) & 25 & (17) \\
\hline Approved indications & 5 & (6) & 4 & (8) & 4 & $(25)$ & 13 & (9) \\
\hline Speed & 4 & (5) & 8 & $(15)$ & 1 & (6) & 13 & (9) \\
\hline Cost & 2 & (3) & 0 & (0) & 2 & $(12)$ & 4 & (3) \\
\hline Precautions and contraindications & 2 & (3) & 7 & $(13)$ & 2 & $(12)$ & 11 & (8) \\
\hline Drug identification information & 1 & (1) & 5 & $(10)$ & 0 & (0) & 6 & (4) \\
\hline Pregnancy and breastfeeding information & 0 & $(0)$ & 2 & (4) & 0 & (0) & 2 & (1) \\
\hline Patient counselling information & 0 & (0) & 4 & (8) & 0 & (0) & 4 & (3) \\
\hline Toxicology & 0 & $(0)$ & 0 & (0) & 0 & (0) & 0 & (0) \\
\hline Other & 6 & (8) & 1 & (2) & 2 & $(12)$ & 9 & (6) \\
\hline
\end{tabular}

*Factors are ordered from most to least important in terms of pharmacists' responses (with "other" presented last).

${ }^{\dagger}$ Each participant was asked to choose the top 3 from a predefined list of factors; therefore, the percentages do not sum to $100 \%$.

\section{Database Usability}

In the side-by-side comparison of the Lexicomp and Micromedex databases across 7 usability domains, Lexicomp was rated higher on screen layout, ease of use, speed, and accuracy, whereas Micromedex was rated higher on sufficiency of information provided, capability to solve drug-related questions, and performance to satisfy participants' needs (Table 4). However, the differences between the databases in terms of these ratings were not statistically significant.

\section{Overall Quality}

The largest proportion of pharmacists $(n=33)$ ranked Micromedex as the drug information database with better overall quality. The largest proportions of nurses $(n=20)$ and other health professionals $(n=8)$ had no preference (Figure 2). Of the 22 nurses who had a preference, most chose Micromedex $(n=13)$.

\section{Overall Preference}

In terms of overall preference, more pharmacists preferred Lexicomp than preferred Micromedex (35 versus 32). Once again, many of the nurses $(n=15)$ and other health professionals $(n=5)$ had no preference (Figure 3 ). Of the 26 nurses who expressed a preference, more picked Micromedex than Lexicomp (14 versus 12).

\section{Preferences in the Context of Database Cost}

Participants were asked to choose the relative price reduction (as a percentage) that would be needed for them to switch to a less preferred database. The largest proportion of pharmacists $(n=21)$ stated that a $70 \%$ cost reduction would be needed to persuade them to switch (Figure 4). Among nursing and other health professionals, the largest proportion had no preference between the 2 databases. 
TABLE 4. Usability Scores for Micromedex and Lexicomp Databases

Database; Mean Usability Score $(95 \% \mathrm{Cl})$ *

Quality Indicator

Micromedex

\begin{tabular}{|c|c|c|c|c|}
\hline Layout of the screens was clear & 3.91 & $(3.72-4.10)$ & 4.09 & $(3.95-4.23)$ \\
\hline Navigating within this database was easy & 3.88 & $(3.67-4.09)$ & 4.07 & $(3.92-4.22)$ \\
\hline Speed of this database was fast & 4.14 & $(3.97-4.31)$ & 4.19 & $(4.07-4.31)$ \\
\hline The content in this database was accurate & 4.02 & $(3.85-4.19)$ & 4.09 & $(3.97-4.21)$ \\
\hline The amount of information provided from this database was sufficient & 4.11 & $(3.92-4.30)$ & 3.72 & $(3.56-3.88)$ \\
\hline This database was able to solve my drug-related questions & 4.04 & $(3.86-4.22)$ & 3.82 & $(3.66-3.98)$ \\
\hline Overall, the performance of this database was able to satisfy my needs & 3.98 & (3.77-4.19) & 3.91 & $(3.75-4.07)$ \\
\hline
\end{tabular}

$\mathrm{Cl}=$ confidence interval.

*The usability score was rated from 1 (strongly disagree) to 5 (strongly agree) on a Likert-type scale.

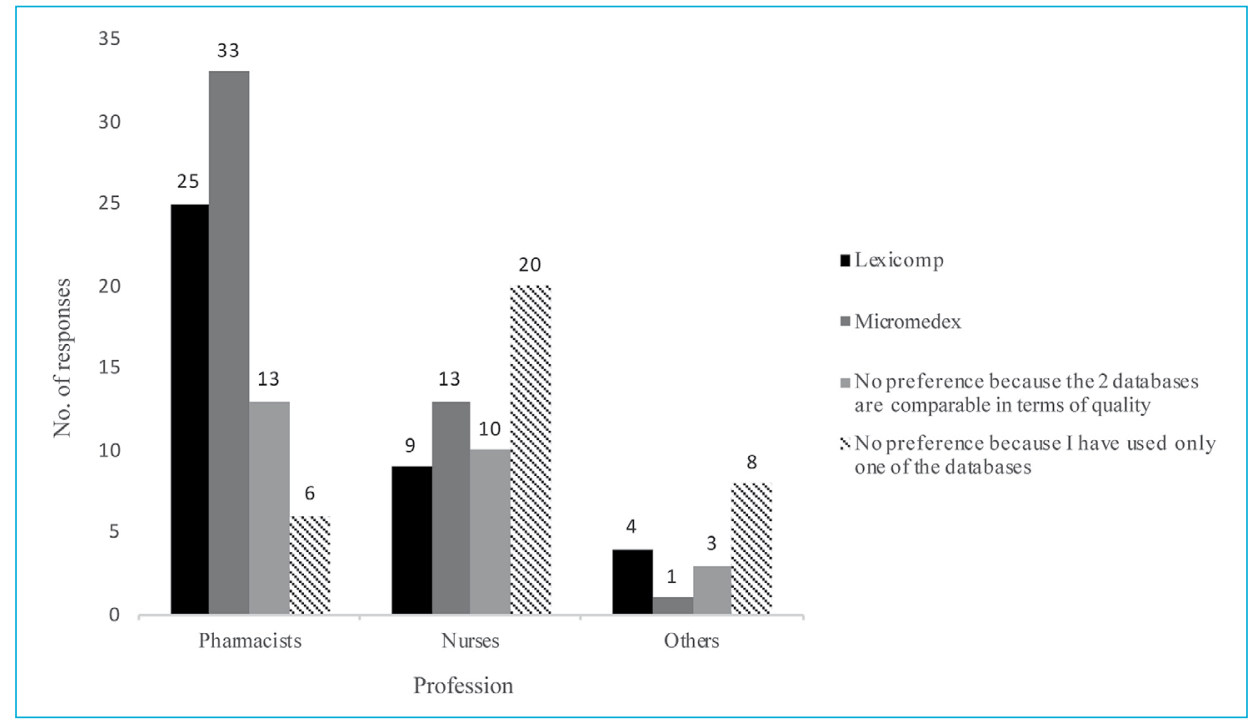

FIGURE 2. Distribution of databases deemed to have better quality, by profession $(n=145)$.

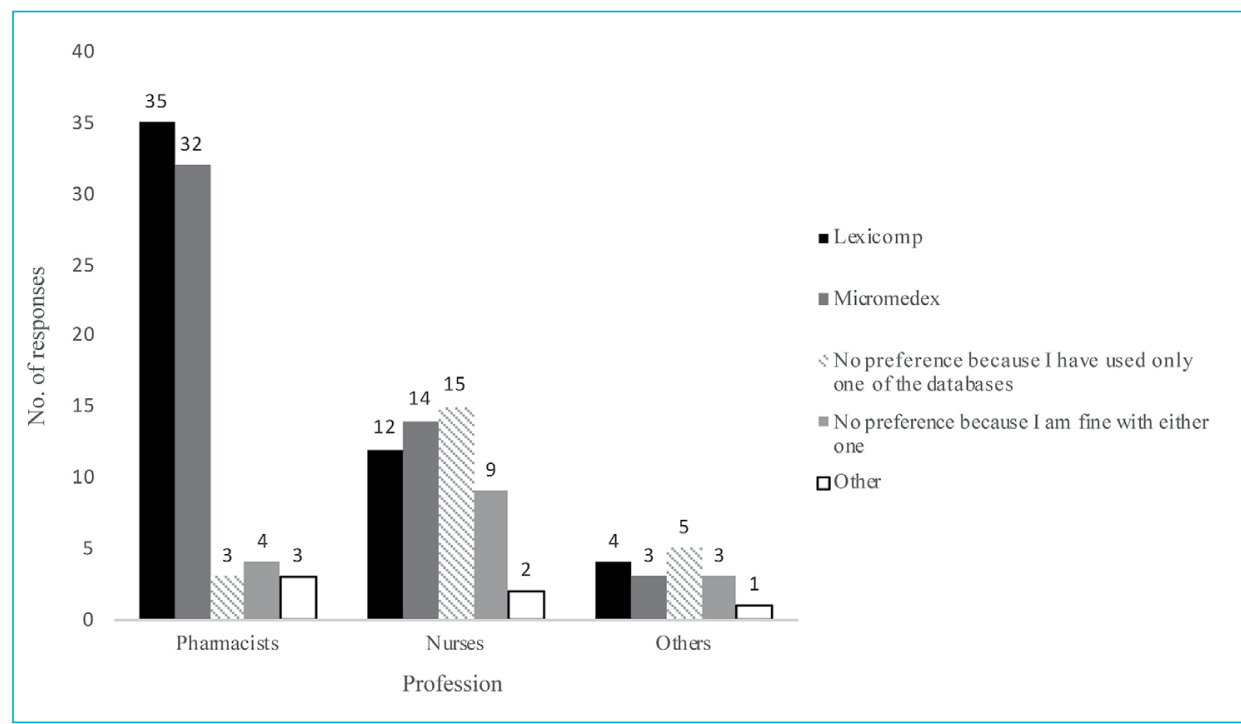

FIGURE 3. Distribution of overall database preferences, by profession $(n=145)$. 


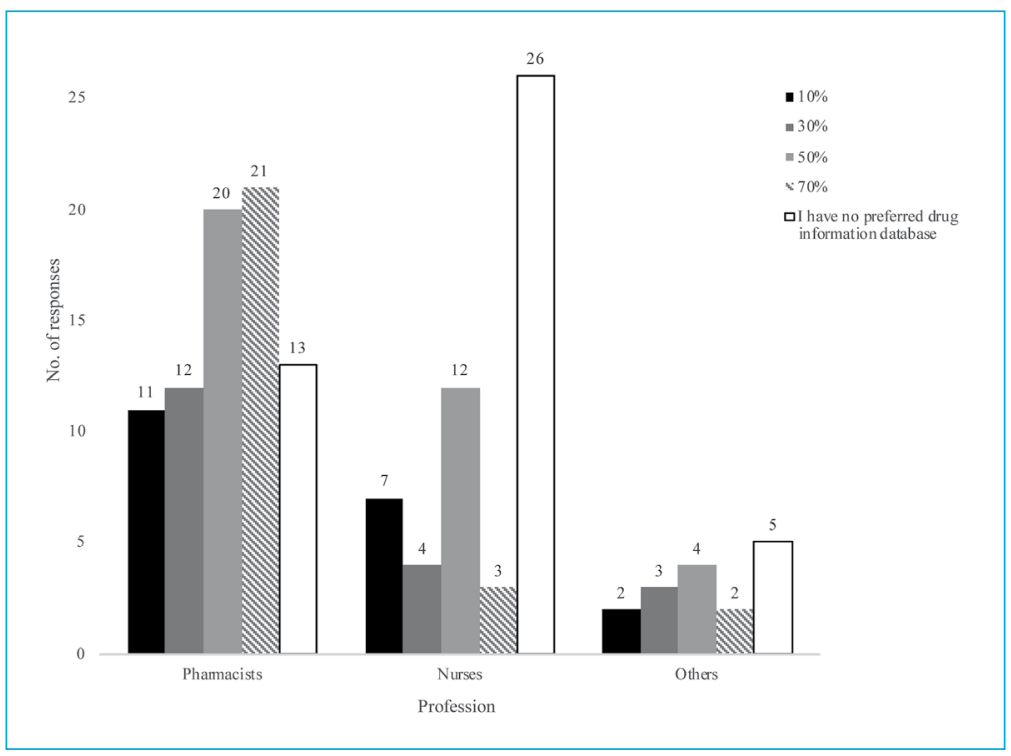

FIGURE 4. Distribution of each health professional's willingness to switch from preferred database, by percent cost reduction $(n=145)$.

\section{DISCUSSION}

With the rising number of new medications in the 21st century, online drug information databases have become a necessity for health professionals in the provision of patient care. In the face of budget constraints, the health authorities in the Lower Mainland of British Columbia can subscribe to only a single electronic drug information database at any given time. These subscriptions are contract-based and require periodic renewal, typically every 3 to 5 years. Contract renewal often presents an opportunity for the health authorities to re-evaluate the performance of the current drug information database and determine whether it still meets the needs of health professionals. It is also a chance to investigate any new and improved databases on the market. Cost is undoubtedly a major consideration in the subscription decision, but user preferences and other factors should be taken into account as well. Therefore, as a program evaluation study, we created an online survey with the primary objective of determining the main factors that health authority staff in the Lower Mainland consider when choosing a web-based drug information database. These factors are essentially timeless, such that decision-makers can refer to our findings again in 3 to 5 years' time, when the next contract ends. In addition, with free trial access to the web-based Micromedex database available to health authorities during the study period, our secondary objective was to determine health professionals' preference between the Lexicomp and Micromedex databases.

Drug information databases evolve over time, so having an up-to-date list of factors that health professionals consider when choosing a web-based drug information database can be valuable for decision-makers. In a study published in 2005, Galt and others ${ }^{2}$ found that physicians listed frequency of update, ease of use, degree of usefulness, and drug reaction information as the most heavily weighted indicators in choice of a database. In a study published in 2008, Gettig ${ }^{7}$ concluded that health professionals, including pharmacists, physicians, and nurses, deemed trustworthiness and accuracy as the 2 most important elements of a drug information database. Our study augments this previous literature because our survey was open to all health professionals, and we found that, consistent across all professions, ease of use and dosing information were the 2 leading factors considered in selecting a drug information database. Our results parallel those of Galt and others ${ }^{2}$ by showing not only that content (such as drug dosing information) is important in a drug information database, but also that users place heavy emphasis on technical aspects (such as ease of use). Decision-makers may want to consider scoring both content and technical aspects when they are choosing between online drug information databases for future subscriptions.

Health authorities in the Lower Mainland of British Columbia have been subscribing to the Lexicomp product for the past 6 years, with the exception of the Provincial Health Services Authority, which has held subscriptions to both Lexicomp and Micromedex. Therefore, only some health professionals are familiar with both databases. However, the recent availability of free access to the Micromedex database for the Lower Mainland health authorities permitted all health professionals to test both databases. Previous studies have had conflicting results regarding health professionals' perspectives toward Lexicomp and Micromedex. Among 8 studies conducted between 2002 and 2017, Lexicomp was the preferred drug information database in 
3 studies ${ }^{2,5,8}$ and Micromedex was the database of choice in only 1 study. ${ }^{9}$ In the 4 remaining studies ${ }^{10-13}$ the Lexicomp and Micromedex databases were found to be comparable, as we observed in the current study. In our side-by-side statistical comparison of the 2 databases, we found that the Lexicomp database was rated higher on technical aspects such as layout, navigation, and speed, whereas the Micromedex product was rated higher on content aspects such as sufficiency of information and ability to solve drug-related questions. These results matched previous findings that Lexicomp is easier to navigate whereas Micromedex has more detailed content. ${ }^{2,10-12}$ Our results are important because they suggest to decision-makers that Lexicomp and Micromedex are currently comparable and that both meet the needs of health professionals.

To elaborate on the pharmacists' input to this study, we noticed a difference in responses between the question about overall quality of the database and the question about participants' overall database preference. We assumed that the database deemed to have better quality would also be the database preferred by most participants. To confirm this assumption, our survey purposely included the following 2 consecutive questions: "Which would you consider to be a drug information database with better quality?" and "If you only had access to one drug information database, which one would you prefer?" Most pharmacists picked Micromedex for the first question (concerning quality), but most pharmacists chose Lexicomp for the second question (concerning their personal preference). The increase in number of respondents who chose Lexicomp as the preferred database was mainly due to the 13 pharmacists who indicated in the first question that the 2 databases were of similar quality. When it comes to preferences, even though pharmacists thought Micromedex was the better-quality database, most preferred to use Lexicomp. Acknowledging participants' perceptions of Lexicomp as being superior to Micromedex in terms of its technical aspects, we can infer that pharmacists preferred Lexicomp because of its ease of use. With Lexicomp being the go-to resource in British Columbia for the past several years, participants may also have favoured the database that was more familiar. ${ }^{14}$ The results of these 2 questions support our primary objective: not only is content accuracy important, but drug information databases should also be intuitively easy to operate.

When health authorities are subscribing to a drug information database, cost plays an important role. To evaluate the importance to health professionals of having access to their preferred drug information database, we asked participants about their willingness to switch to a less preferred database in relation to cost. Pharmacists most frequently chose $70 \%$ as the relative price reduction that would be required to justify a switch away from their preferred database, with a $50 \%$ reduction being the secondmost frequent price point. In contrast, most other health professionals had no preference between the databases. Although the relative discount might have been different if we had provided actual cost data in the survey, we found the requested hypothetical discount somewhat informative for determining respondents' preferred electronic drug information database over an alternative. These results suggest that pharmacists are more particular about the resources they prefer to use; it is therefore important for pharmacists to have access to their preferred drug information database, because most were not willing to switch to a less-than-ideal database until it was $70 \%$ cheaper. Decision-makers should keep this in mind when deciding between databases in the future.

\section{Strengths and Limitations}

Our survey provided a summary of what some BC health professionals value in an online drug information database. The major strengths of this survey include its capability to illustrate health professionals' preference regarding the importance of drug content as well as user-friendliness in a drug information database. This survey was also one of the first to consult other $\mathrm{BC}$ health professionals, in addition to pharmacists, for their opinions about electronic drug information databases.

However, this evaluation had several limitations. The primary limitation was the response rate. We adopted a convenience sampling method, whereby the survey link was sent to directors or managers for further distribution to health professionals other than pharmacists; as such, the number of potential respondents reached was essentially unknown, and a response rate could not be calculated. In spite of this limitation, participants in this survey were similar, in terms of years of practice and primary roles in practice, to health professionals in British Columbia. ${ }^{6}$ Nonetheless, future studies, with ability to calculate the response rate and efforts to encourage a high response rate, are recommended to improve the validity of our survey results and hence address the potential nonresponse bias of our study.

The design of our survey contributed to several limitations in our results. First, despite the online survey's capability to save partial responses, allowing participants to return later to pick up where they left off, we could not rule out the possibility that some participants repeated the survey; any duplicate responses would have interfered with the interpretation of our results. Second, participation in the survey was entirely voluntary, so the information captured would represent the participants who wanted their voices heard, resulting in potential sampling bias. Third, a discrepancy between the number of responses received $(n=247)$ and the number of surveys completed $(n=145)$ indicates a low completion rate, which may indicate that participants had trouble navigating the online survey. Fourth, we did not specify in the survey materials that it was our intention to seek participants' opinions about the web-based versions of 
Micromedex and Lexicomp (not the app-based versions). It is unknown whether participants were answering the questions based on their experience with the web-based and/or the app-based drug information databases, although when interpreting our results, we assumed that participants were answering the questions based on experience with the webbased versions only. Fifth, for the cost question, we offered options in terms of relative cost reductions, instead of giving information about the actual cost of a drug information database. Although this approach improved the general applicability of our results for future subscription decisions, the results were highly subjective and might have been different if participants had been given known costs. Finally, we recognize that some health professionals had no prior experience with the Micromedex database, and their limited exposure to this database (through the trial access available during the study period) might have been too brief to allow accurate evaluation of their true preference between the 2 databases.

\section{CONCLUSION}

This is one of the first surveys showing that dosing information and ease of use were the 2 most influential factors for $\mathrm{BC}$ health professionals when deciding on an online drug information database. Study participants indicated no significant differences in usability, overall quality, and user preference between Micromedex and Lexicomp, the 2 most commonly subscribed databases by BC health authorities. Most pharmacists indicated that a database would have to be at least $70 \%$ cheaper than their preferred database to justify switching, whereas most other health professionals had no preference. These findings should be considered in future decisions about drug information database subscriptions.

\section{References}

1. Mountford CM, Lee T, De Lemos J, Loewen PS. Quality and usability of common drug information databases. Can J Hosp Pharm. 2010; 63(2):130-7.

2. Galt K, Rule A, Houghton B, Young D, Remington G. Personal digital assistant-based drug information sources: potential to improve medication safety. J Med Libr Assoc. 2005;93(2):229-36

3. Kuperferberg N, Hartel LJ. Evaluation of five full-text drug databases by pharmacy students, faculty, and librarians: do the groups agree? J Med Libr Assoc. 2004;92(1):66-71.
4. Campbell R, Ash J. An evaluation of five bedside information products using a user-centered, task-oriented approach. J Med Libr Assoc. 2006; 94(4):435-e207.

5. Donohoe K, Matulewicz A, Alotaibi F, Ogbonna K. Medical apps used during advanced pharmacy practice experiences. Curr Pharm Teach Learn. 2018;10(2):195-200.

6. Health workforce, 2018: indicators. Canadian Institute for Health Information; 2019 [cited 2019 Jul 19]. Available from: http://www.cihi.ca/ sites/default/files/document/hwdb-2018-indicators-en-web.xlsx

7. Gettig J. Drug information availability and preferences of health care professionals in Illinois: a pilot survey study. Drug Inform J. 2008;42(3): 263-72.

8. Hanrahan C, Cole S. Assessment of drug information resource preferences of pharmacy students and faculty. J Med Libr Assoc. 2014;102(2):117-21.

9. Hailemeskel B, Drame I, Pansiri P, Choi M. A survey of preference and utilization of drug information resources by pharmacy students. $A d v$ Pract Nursing. 2016;1(3). doi: 10.4172/2573-0347.1000122.

10. Clauson KA, Polen HH, Marsh WA. Clinical decision support tools: performance of personal digital assistant versus online drug information databases. Pharmacotherapy. 2007;27(12):1651-8.

11. Rehman B. Micromedex and Lexicomp: considerations to aid choice between products. UK Medicines Information; 2011 [cited 2019 Jul 19]. Available from: https://www.ukmi.nhs.uk/filestore/ukmiacg/MI databases_comp2011.pdf

12. Chatfield A. Lexicomp Online and Micromedex 2.0 [comparative review]. J Med Libr Assoc. 2015;103(2):112-3.

13. Moorman K, MacDonald E, Trovato A, Tak C. Assessment and use of drug information references in Utah pharmacies. Pharm Pract. 2017;15(1):839.

14. Belgado B, Hatton R, Doering P. Evaluation of electronic drug information resources for answering questions received by decentralized pharmacists. Am J Health Syst Pharm. 1997;54(22):2592-6.

Yiu-Ching Jennifer Wong, PharmD, was, at the time this study was performed, a PharmD candidate (Class of 2020) in the Faculty of Pharmaceutical Sciences, The University of British Columbia, Vancouver, British Columbia. She is now a Pharmacy Resident with Lower Mainland Pharmacy Services in British Columbia.

Candy Lee, BSc(Pharm), ACPR, is a Clinical Pharmacist with Surrey Memorial Hospital, Surrey, British Columbia.

Adil Virani, BSc(Pharm), PharmD, FCSHP, is Manager of Pharmacy Services with Lower Mainland Pharmacy Services, and is also a Clinical Associate Professor with the Faculty of Pharmaceutical Sciences, The University of British Columbia, Vancouver, British Columbia.

Competing interests: None declared.

Address correspondence to:

Dr Yiu-Ching Jennifer Wong Department of Pharmacy Services

Surrey Memorial Hospital

13750 96th Avenue

Surrey BC V3V 1 Z2

e-mail: Jenniferwongyc@alumni.ubc.ca

Funding: None received. 